\title{
DESAFIOS EM ADEQUAR O ENSINO A DISTÂNCIA EM UM APRENDIZADO SEM "DISTÂNCIA"
}

\section{ARTIGO ORIGINAL}

BATISTA, Carlos ${ }^{1}$

BATISTA, Carlos. Desafios em adequar o ensino a distância em um aprendizado sem "distância". Revista Científica Multidisciplinar Núcleo do Conhecimento. Ano 05, Ed. 01, Vol. 10, pp. 83-95. Janeiro de 2020. ISSN: 2448-0959, Link de acesso: https://www.nucleodoconhecimento.com.br/educacao/aprendizado-semdistancia

\section{RESUMO}

O presente estudo visa discutir, de forma breve, sobre o panorama atual da modalidade de ensino a distância, sua história, desafios e propostas tanto sob à ótica do professor como também a partir da do aluno, com o objetivo de obter aprimoramentos nos métodos de ensino atuais. $\mathrm{O}$ artigo também aborda as gerações do Ensino EAD e suas principais características e finaliza relatando as dificuldades tantos dos alunos que optam por este tipo de ensino como também dos docentes e tutores que aceitam o desafio de ensinar conceitos por meio de plataformas de ensino a distância. É cada vez mais presente docentes e discentes que optam por quebrar e desmistificar o paradigma tradicional da sala presencial migrando para à sala virtual com contatos pedagógicos remotos. As considerações finais chamam atenção acerca das necessidades do aluno em buscar, incessantemente, a motivação, a disciplina e o engajamento nos estudos o qual está vinculado, as mesmas qualidades devem

1 Pós-graduado em Metodologia do Ensino da Língua Inglesa (Faculdade de Educação São Luís); Pós-graduado em MBA em Marketing e Vendas (FMU); Pósgraduado em Formação em Educação a Distância (UNIP); Pós-graduando em Docência do Ensino Superior (FMU); Bacharelado em Desenho Industrial (FAAP); Graduando em Letras (UNIP). 
servir de estímulo para os docentes e tutores EAD, cujo papel é importantíssimo para com seus alunos e fundamental para continuidade e aprimoramento deste modelo de ensino.

Palavras-chaves: Ensino, EAD, aluno, professor, educação.

\section{INTRODUÇÃO}

É consenso que o sistema de Ensino EAD para cursos de graduação, extensão, pósgraduação e muitas disciplinas da educação básica se tornam cada vez mais presentes e necessários no âmbito educacional nacional, sendo, inclusive, incentivados pelo governo por meio de decretos e portarias (MINISTÉRIO DA EDUCAÇÃO E DESPORTO, 1998). Porém este universo promissor que se descortina ainda carrega inúmeros problemas. Assim, é preciso entender que o modo de ensino a distância não pode ter como objetivo principal resolver problemas educacionais, mas sim ser uma nova e potencial opção para alunos que tem limitações de tempo ao longo do dia (CASTRO; GENGHINI, 2019) ou que tenham dificuldades de deslocamentos presenciais para centros educacionais em cidades de maior porte.

A questão é que os alunos que optam por essa modalidade, em muitas das vezes, não estão preparados para um aprendizado à distância no qual podem ter autonomia para gerenciar seu tempo e forma de estudo. Entende-se que apesar da euforia inicial, eles se sentem perdidos em um segundo momento, fato que pode ser comprovado, inclusive, pelos altos índices de desistências dos cursos (GUIA DO ESTUDANTE, 2017). Da mesma forma, percebemos que os professores não estão, totalmente, adaptados ao conceito EAD, visto que adotam métodos de ensino de um sistema presencial. Devido ao pouco uso de ferramentas e plataformas disponíveis e, principalmente, por pouca prática na interação com o aluno que se comunica agora de forma essencialmente virtual. O formato do ensino se mostra promissor e em consonância com nossa realidade digital, mas ainda pouco eficiente em vários aspectos. 


\section{OS CONCEITOS E GERAÇÕES DA MODALIDADE DE ENSINO EAD}

Muito disseminado na atualidade e alardeado por alguns estudiosos (MORAN, 2011; ALVES; ZAMBALDE; FIGUEIREDO, 2004) como o futuro da educação, o sistema de ensino a distância ou comumente entendido como Ensino EAD é visto como a solução para alguns problemas crônicos da educação no mundo e no Brasil: dentre eles ter uma educação acessível e inclusiva:

[...] percebermos que [...] EaD não é uma simples veiculação de informações instrucionais, mas um processo pedagógico humano, uma construção de conhecimento, porque é muito mais do que recepção de informação e aquisição de conhecimento. É construção efetiva, tendo o professor como facilitador de aprendizagem. Percebemos que esse tipo de aprendizagem é centrada no aluno, o qual tem sob sua responsabilidade a estruturação de uma atitude proativa, o que exige não só maturidade, como organização, autonomia e autodisciplina para o processo de construção do conhecimento (CASTRO; GENGHINI, p. 22, 2019).

Em seu estudo, Castro e Genghini (2019) reiteram que há algo perceptível em nossa sociedade conectada, se podemos trabalhar a distância, consumir a distância e até nos relacionarmos com pessoas virtualmente, por que não estudar à distância também? 
Figura 1 - Ensino EAD

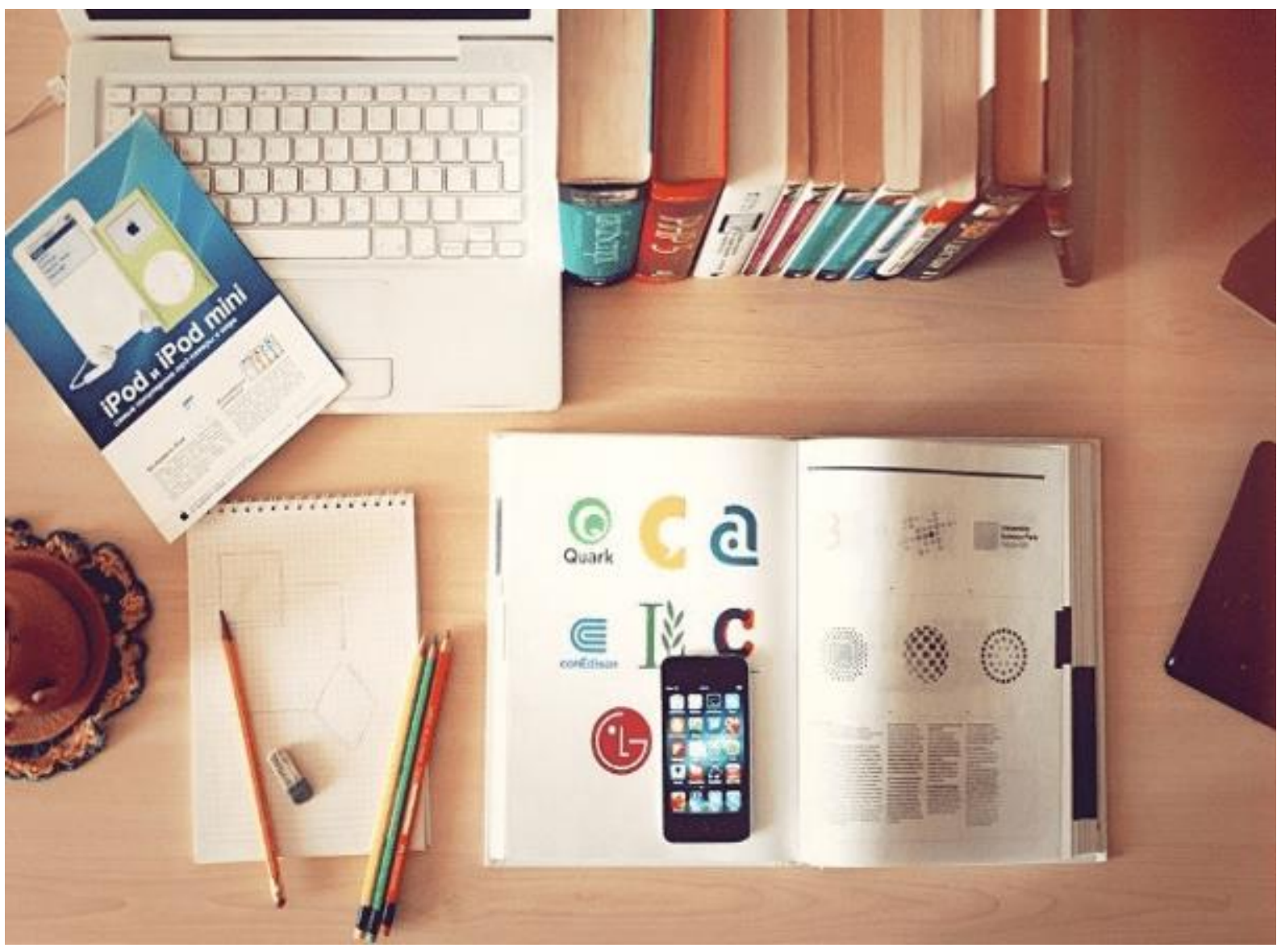

Fonte: Pixabay (2019)

A tecnologia da uma mãozinha, ajuda o que antes era demorado e sem interação. Mas, o que vivenciamos hoje, demorou um certo tempo para ser amadurecido e aprimorado. O ensino a distância vivenciou gerações e, em cada uma delas, novos aprimoramentos foram possíveis e novos recursos foram integrados. Existe um entendimento hoje de que temos, pelo menos, 5 gerações de EAD e que estamos vivenciando a última.

\subsection{AS GERAÇÕES DO ENSINO EAD}

A primeira geração iniciada no século XVIII abriu o caminho para qualquer aluno aprender saberes variados, porém, sempre por correspondência. Santos $(2016$, p. 17) ressalta que: "a primeira geração, [...] é marcada pela comunicação textual [...], ou 
seja, à correspondência como canal de interação entre aluno e professor [...]". Santos (2016, p. 17) ainda exemplifica que: "[...] o emprego da correspondência como disseminadora de conteúdos. [...] é conhecido como 'estudo em casa' ou 'estudo independente', mas sem planejamento formal [...]". Este formato perdurou até 1920, quando teve início a popularização da informação por outros meios, como, por exemplo, o rádio, e, posteriormente, a televisão.

A segunda geração do EAD marca, justamente, este novo período no qual, inicialmente, o rádio teve uma importância muito grande até à primeira metade do século XX culminando, posteriormente, com a televisão como mídia para alicerçar e massificar o aprendizado para qualquer interessado. Já a terceira geração é marcada pelo uso intensivo de ferramentas interativas e computacionais para o ensino/aprendizagem. Iniciou já no final do século XX e começo do século XXI. A partir dela, as Tecnologias de Informação e Comunicação ou TICs tornam o Ensino EAD popular, democrático e acessível, permitindo o uso de ferramentas síncronas (na qual todos estão ao mesmo tempo conectados) ou assíncronas (não conectados ao mesmo tempo) como uma nova dimensão a ser explorada durante a aprendizagem dos alunos.

A penúltima geração é à quarta, ela molda, em boa parte, o que conhecemos hoje como o Ensino EAD contemporâneo, além de utilizar ferramentas síncronas e assíncronas, ela traz o conceito de e-learning (aprendizado à distância) factível graças à internet e redes sociais cada vez mais populares e presentes em nosso meio (GONÇALVES, 2007). A quinta e última geração é caracterizada pelo uso intensivo de ambientes virtuais no ensino, e, assim, novos métodos são possíveis como a gamificação (utilização de jogos no qual o aluno pode coordenar ações) e salas e laboratórios virtuais cuja premissa principal é o aprendizado com base na interação (GARCIA; GENGHINI, 2019). Em especial está última geração resume a necessidade intrínseca da educação acompanhar uma sociedade interativa, ágil e conectada. Toda esta evolução também é denominada de Educação 3.0. 


\subsection{EDUCAÇÃO 3.0}

Evoluir o sistema educacional e inovar em métodos de ensino só foi possível com o advento do mundo digital. Margall (2013) detalha a questão em seu estudo e afirma que:

[...] a educação 3.0 depende pesadamente de sofisticadas infraestruturas e aplicações tecnológicas. É somente num mundo digital, conectado e interativo que a educação 3.0 acontece. Sem a tecnologia, o sonho de dar um tratamento único e sob medida para cada criança, cada aluno, nos faria voltar ao século XVIII, quando havia um tutor para cada aluno (MARGALL, 2013).

Deve-se observar que as melhores práticas educacionais entendidas hoje se espelham em ideias passadas. Mas é fato que antes mesmo de pensarmos em uma sala de aula no formato tradicional (virtual ou não), mestres ensinavam seus conhecimentos individualmente aos seus alunos tutelados ou até mesmo em grupos reduzidos (CRUZ, 2015). Com isto, o aproveitamento máximo dos conceitos era praticamente garantido, além disto, os tutores poderiam acompanhar de perto a evolução do aluno e realizar, a partir da análise de tal progresso, avaliações personalizadas de acordo com o grau de entendimento interiorizado, lição após lição.

A educação 3.0 já é realidade e urge em ser prontamente implementada no cenário nacional em definitivo (LUIZ; SILVA, 2014). É impensável e improdutivo estudar sem um computador ou até mesmo sem uma conexão internet, atualmente. O árduo trabalho que bibliotecas físicas faziam em catalogar inúmeros exemplares com milhões de informações a disposição de seus usuários não se compara em quantidade e variedade que os sites buscadores na web proporcionam na atualidade. Porém nem tudo é poesia, se o novo sistema de ensino se mostra promissor, ainda existem (muitas) dificuldades por parte de quem aprende e de quem ensina e vamos entendêlas melhor nos próximos tópicos. 


\section{AS DIFICULDADES ENCONTRADAS PELOS ALUNOS}

Tori (2010), em seu estudo, parte do pressuposto de que no processo de ensinoaprendizagem o aluno não deve estar distante do professor, mesmo que o aprendizado seja a distância, pois acredita que as tecnologias atuais e as inúmeras práticas que surgiram como, por exemplo, a sala de aula invertida, unem essas duas pontas de forma cada vez mais próxima e conectada em tempo real. O objetivo é superar a ideia que se criou que o aprendizado ocorre apenas em uma sala de aula e com livros didáticos.

Está conexão entre docente e discente de forma totalmente síncrona dentro de um contexto de ensino a distância que seria impensável algumas décadas atrás (GERVAl; GENGHINI, 2019). Hoje ela não é só possível como necessária para uma completa assimilação dos conteúdos aprendidos a partir de um respaldo maior do professor (conteudista) que ministra ou mesmo orienta os ensinamentos. Tanto que se faz necessária para sanar dúvidas e acompanhar os trabalhos dos alunos e sua evolução (ou não) em cima de todo contexto pedido (PRADO; MARTINS, 2001).

Figura 2 - Aluno em dificuldade

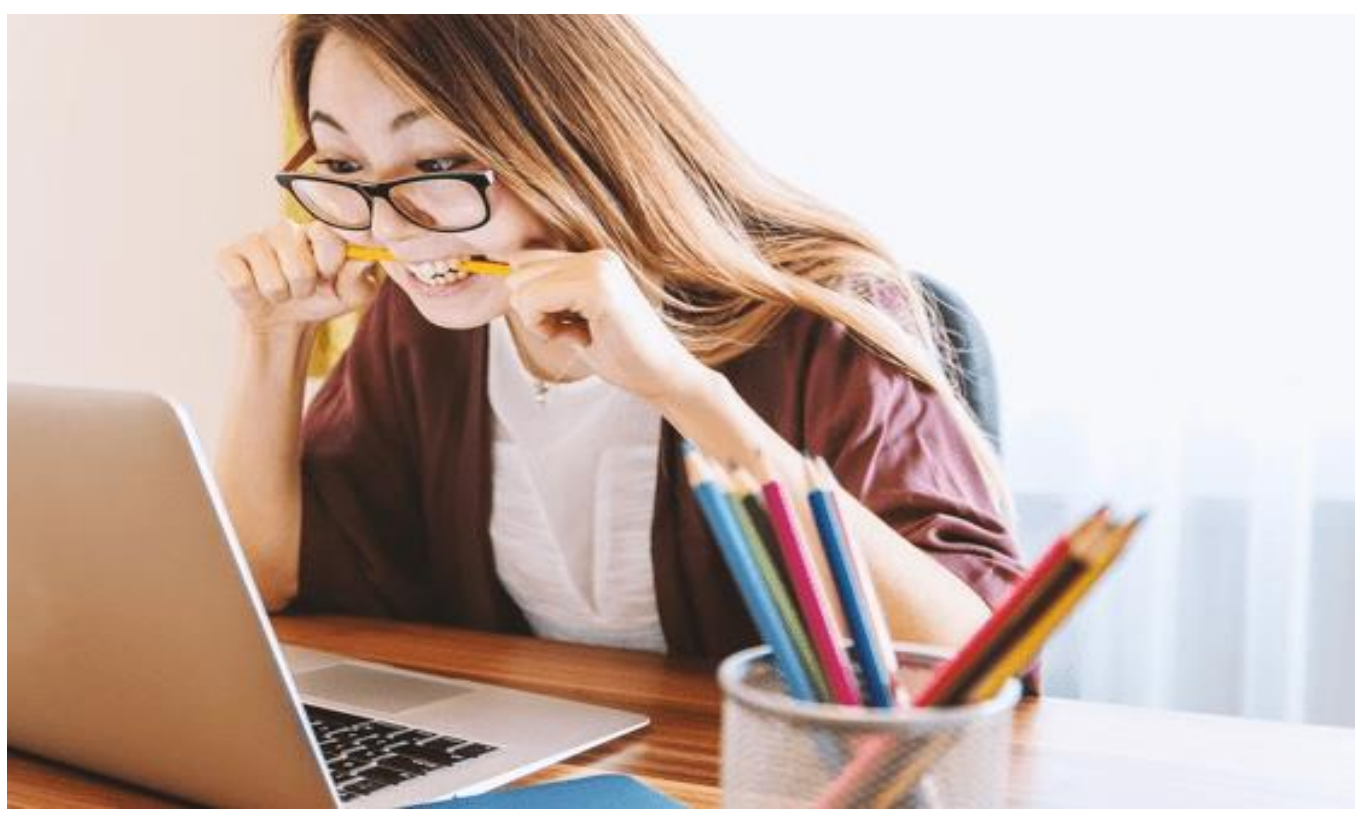

Fonte: Pixabay (2019). 
O problema é: o que parece óbvio em ter a necessidade de uma conexão simples, direta e objetiva entre aluno e professor no ensino a distância, não parece acontecer, de fato, na prática. Ainda é visível algumas dificuldades observadas:

\subsection{PROFESSORES QUE EXPLICAM BEM E PROFESSORES QUE NÃO "EXPLICAM NADA"}

Provavelmente isto se deve, em boa parte, à falta de experiência dos professores no uso e exploração de novas tecnologias em uma sala de aula virtual (BERGMANN; SAMS, 2015). Convivemos, ainda, com educadores formados a partir de um tipo de ensino anterior a Geração Z (MEIR, 2017), isto significa, na prática, que professores formados a 20, 15 ou 10 anos atrás tendem a ter uma dificuldade maior em lidar com um modelo de ensino não presencial. O resultado é um baixo aproveitamento e rendimento por parte dos alunos, como observamos anteriormente.

\subsection{AVALIAÇÕES SEM JUSTIFICATIVAS SUFICIENTES OU CONVINCENTES}

É o caso da ineficiência no acompanhamento dos trabalhos propostos aos alunos, no qual, em muitas das vezes, são descriminadas notas com poucas justificativas. Se já é difícil para o aluno se ambientar em uma plataforma multinível (GERVAI; GENGHINI, 2019) imagine para o docente que precisa emitir detalhados feedbacks dos trabalhos analisados. O resultado é o reflexo direto de más notas por conta de alunos desestimulados e descontentes.

\subsection{NÃO ENTENDIMENTO DOS OBJETIVOS PROPOSTOS E METAS A SEREM OBSERVADAS NA DISCIPLINA E NA GRADUAÇÃO}

Apesar da boa-vontade de coordenadores e professores em expor o conteúdo a ser ministrado, termos como plano de ensino e conteúdo programático são conceitos totalmente desconhecidos por boa parte dos alunos. Para embasar melhor, abaixo é detalhado um plano de ensino desenvolvido para uma plataforma de Ensino EAD de uma universidade privada: 
O plano de ensino apresenta informações relevantes para que você, aluno(a), possa compreender a finalidade da disciplina a ser estudada e importância na sua formação. Sugerimos que leia antes de iniciar seus estudos, poderá auxiliar durante o seu percurso na disciplina. Leia atentamente o plano de ensino da disciplina, assim poderá saber quais são os objetivos e informações importantes para que possa desenvolver e compreender a relevância da mesma na sua formação (AMBIENTE VIRTUAL DE APRENDIZAGEM - UNIP, 2019).

O mesmo plano de ensino, quando apresentado na plataforma, divide-se em, respectivamente: descrição, ementa, objetivos, conteúdo programático, estratégia de trabalho, forma de avaliação e bibliografia utilizada. O que demonstra ser itens absolutamente essenciais para uma melhor compreensão da disciplina e todo contexto a ela atrelado que, na maioria das vezes, passa desapercebido pela maioria dos alunos que a cursam.

\subsection{FALTA DE ENGAJAMENTO APÓS O INÍCIO DOS ESTUDOS CULMINANDO INCLUSIVE EM EVASÕES NOS PRIMEIROS SEMESTRES DOS CURSOS (ESPECIALMENTE OS DE LONGA DURAÇÃO)}

É muito comum a reclamação da falta de apoio pedagógico por parte dos alunos, mesmo que ela exista e esteja presente por meio de vários recursos exemplificados (NAGY; GENGHINI, 2019). Plataformas de estudos (NAGY; GENGHINI, 2019) são, constantemente, atualizadas e técnicas para a diversificação e demonstração das informações são continuamente demonstradas, porém, mesmo assim, ainda se percebe um vácuo entre o que o aluno vê, o que ele capta e o que ele espera aprender. Não queremos adentrar em questões psicopedagógicas da aprendizagem, porém os estudos de Ferdinand Piaget podem esclarecer alguns pontos importantes.

[...] a principal meta da educação é criar homens que sejam capazes de fazer coisas novas não simplesmente repetir o que outras gerações já 
fizeram. Homens que sejam criadores, inventores, descobridores. A segunda meta da educação é formar mentes que estejam em condições de criticar, verificar e não aceitar tudo que a elas se propõe [...] (PIAGET, 1982, p. 246).

Percebe-se que o Ensino EAD ainda precisa se adequar melhor a este aluno receptivo, criativo e inovador que tanto Piaget salientou em seus estudos, muito antes desta modalidade se popularizar no mundo.

\section{AS DIFICULDADES ENCONTRADAS PELOS DOCENTES E TUTORES EAD}

As duas principais dificuldades encontradas, com base em entrevistas e estudos de campo, são resumidas em dois aspectos: a falta de preparo em ministrar e avaliar conteúdos em plataformas on-line e a falta de incentivos e treinamentos voltados à formação contínua de professores para esta área. A distinção entre os dois papéis, o professor conteudista e docente da disciplina e um tutor EAD já se mostra confusa para o cenário educacional, quanto mais para os profissionais da área. Agreste e Genghini (2019, p. 35) procuram exemplificar isto em seus estudos quando caracterizam que: "nos ambientes de aprendizagem do ciberespaço como o EAD o professor assume um novo papel [...] transformando-se em professor "conteudista" e/ou tutor". Elas ainda ressaltam, com fins mais didáticos:

A atuação de professores no contexto da educação tanto no presencial quanto a distância, pressupõe a compreensão da mudança de um paradigma educacional que se atrela à demanda por cidadãos mais autônomos e competentes para atuarem numa sociedade que passou da sociedade da informação para a sociedade do conhecimento, também pressupõe a compreensão das questões do ensino aprendizagem (AGRESTE; GENGHINI, 2019, p. 37). 
Como vimos, exercer a função de tutor EAD tem por objetivo acompanhar o aluno, mitigar suas dúvidas e exercer o trabalho de ponte entre o professor "titular" da disciplina ou do professor expositor do conteúdo com o seu maior interessado: 0 aluno.

Figura 3 - Professor em sala de aula

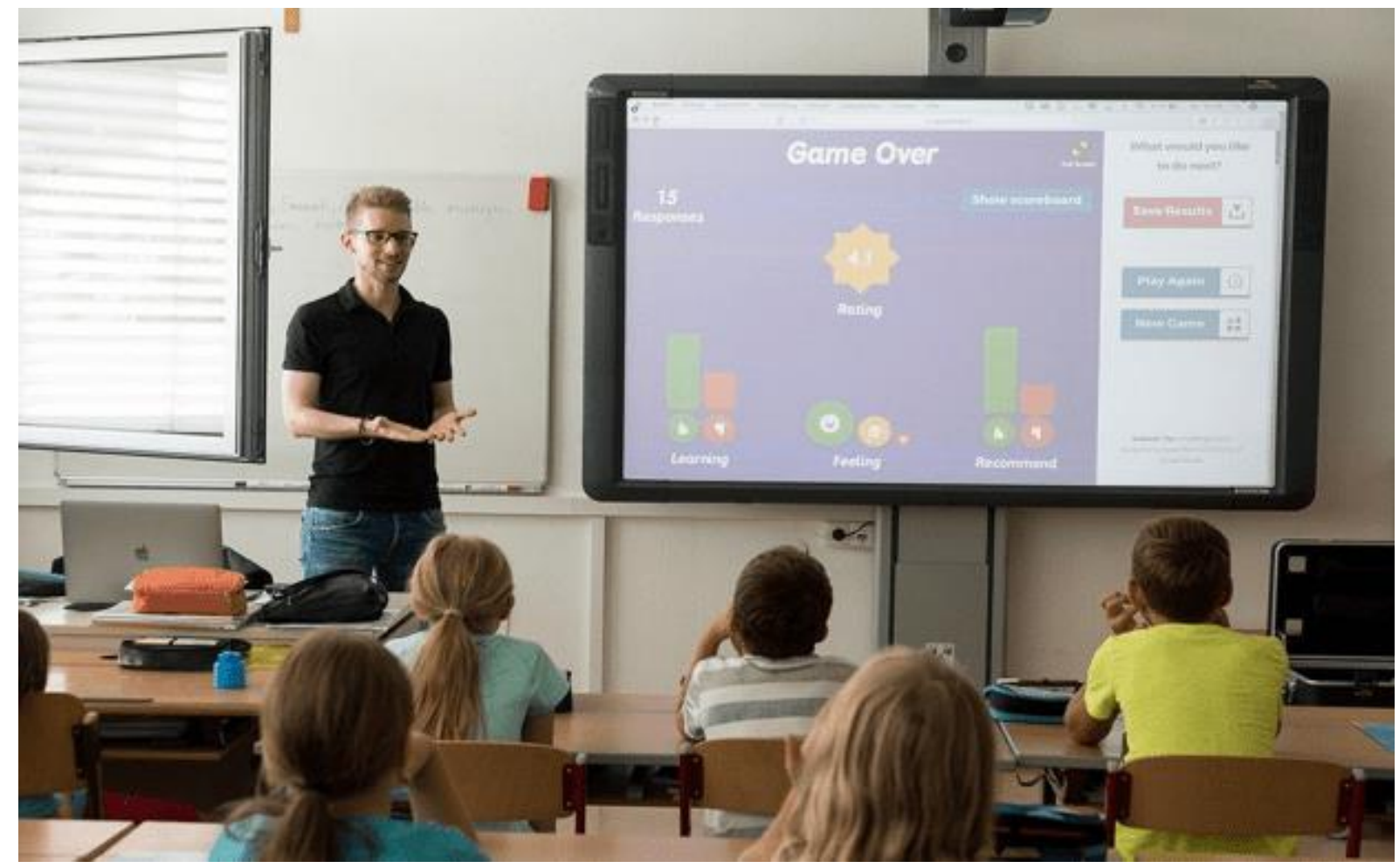

Fonte: Pixabay (2019).

Já o professor responsável pelos conteúdos tem como principal objetivo repassar os conhecimentos exemplificados de forma clara, objetiva e, se possível, no menor tempo factível. Devemos ressaltar que o perfil do aluno EAD é diferente (GONZALEZ, 2009) e suas características principais devem ser: a autonomia, o comprometimento, a curiosidade e o domínio da plataforma que está estudando. O que o difere muito do aluno presencial, especialmente na forma com as quais os conteúdos devem ser abordados. Um dos maiores problemas em todo este contexto é que, em muitas das vezes, os professores (ou tutores) não estão preparados para lidar com o aluno EAD de forma mais eficiente. Ou até pior, eles lidam com o aluno com base em métodos tradicionais de um ensino presencial. 
Temos, então, uma adaptação no ensino que não perdura por muito tempo, uma vez que é a ponta final, isto é, o aluno irá perceber e entender, cedo ou tarde, que pelos conteúdos administrados ou por conta das suas avaliações fora da média o curso em que está matriculado não está sendo bem administrado. Essas dificuldades já são sentidas e estudadas na área pedagógica (GONZALEZ, 2009). Cursos de extensão e pós-graduações são oferecidos e teses são elaboradas, mas a base principal de professores que se voltam, principalmente, ao ensino na educação básica, mostra-se distante e até mesmo perdida com todos os novos conceitos. E não é para menos, a tecnologia nos trouxe benefícios incomensuráveis e progressos inimagináveis em nosso meio, mas o preço a se "pagar" é sermos indivíduos constantemente inclusos (AGRESTE; GENGHINI, 2019).

\section{CONSIDERAÇÕES FINAIS}

A expressão: "estar mais próximo do aluno" deve ser levada ao pé da letra cada vez mais dentro do cenário $E A D$, isto não significa, somente, utilizar de tecnologias assistivas (GARCIA; GENGHINI, 2019) com o propósito de não isolar o aprendizado dos conceitos, mas sim garantir um contato pessoal muito mais presente ao longo dos seus estudos. Ao compreender a perspectiva do aluno é importante perceber e desenvolver sua autonomia e motivação, como exemplificam Agreste e Genghini (2019) quando relatam os fatores de motivação de uma pessoa que podem ser adaptados ao ambiente de estudos:

- O indivíduo (o aluno) percebe uma necessidade ou até mesmo uma carência;

- Através desta necessidade pode se gerar um motivo;

- Através do motivo se leva a uma ação;

- A ação visa satisfazer a necessidade anteriormente apontada;

- Satisfazendo a necessidade é gerado um equilíbrio interno da pessoa e um conceito de auto realização.

Porém isto só é possível com a ruptura de paradigmas, ou seja, com a adesão a ideia do aluno receptivo, pronto para absorver conhecimentos, interessado e com objetivos claros sobre o que busca, entretanto são aspectos ainda distantes da realidade 
vivenciada. A quantidade de informações em que somos constantemente bombardeados causa um efeito nocivo em nossos aprendizados e isto faz com que surja a falta de foco. Confundir os objetivos e metas ao longo dos estudos, desestimular uma motivação construída e embaralhar o poder de absorção de qualquer conhecimento são seus efeitos mais nocivos. A disciplina necessária e salutar de horários de uma escola tradicional vai por água baixo no Ensino EAD, pois o que manda é sua flexibilidade. Mas o que iremos fazer com a organização dos estudos dos alunos?

Entender que vivenciamos um novo paradigma da educação no qual a universalidade do conhecimento é algo natural, espontâneo (VARGAS; GOULART, 2008) permite, ao docente, mudar o seu foco de ensino. Os alunos passam a não ser tratados como meros receptores, mas agentes ativos que compartilham os conhecimentos demonstrados, podendo, então, tirar suas próprias conclusões e realizar suas próprias avaliações, se bem conduzidos. É preciso tratar aqueles que recebem os ensinamentos com maior liberdade e, principalmente, deve haver uma melhor flexibilidade para que a modalidade de ensino à distância seja eficiente, sem nunca deixar de lado suas responsabilidades.

Não raro, há o desinteresse em visualizar os conteúdos, a perda de prazos ou até mesmo a falta de prática com uma metodologia de ensino nova para muitos que estão acostumados à rigidez dos ensinos presenciais. Para os dois lados (docentes e alunos) é importante observar o Ensino EAD como uma oportunidade de conciliar, de forma prática, os estudos com outras responsabilidades no dia a dia, sem a obrigação de estar presente fisicamente em instituições de ensino. Porém, essa prática inovadora só pode ser concretizada com a efetiva responsabilidade do aluno praticante, com a disponibilidade e entendimento do professor que irá atuar e com o engajamento de ambos com os objetivos propostos durante o processo de ensinoaprendizagem. 


\section{REFERÊNCIAS}

AGRESTE, G. P; GENGHINI, E. B. Comunicação: Professor, Aluno, Tutoria e Suportes. São Paulo: Pós-Graduação Lato Sensu UNIP, 2019. 70 p.

AMBIENTE Virtual de Aprendizagem. AVA. Universidade Paulista. Disponível em: https://ava.ead.unip.br/. Acesso em: 29 dez. 2019.

BERGMANN, J; SAMS, A. Sala de Aula Invertida - Uma metodologia Ativa de Aprendizagem. 1를 ed. São Paulo: Editora LTC, 2016.

CASTRO, H. H. R. de; GENGHINI, E. B. Evolução, Perspectivas e Tendências da EaD. São Paulo: Pós-Graduação Lato Sensu UNIP, 2019. 55 p.

CRUZ, S. A. B. Pedagogia Integrada. São Paulo: Editora Sol, 2015. 108 p.

GARCIA, S; GENGHINI, E. B. Metodologias Ativas e Avaliação da Aprendizagem em Ambientes Virtuais. São Paulo: Pós-Graduação Lato Sensu UNIP, 2019. 146 p.

GERVAI, S. M. S; GENGHINI, E. B. Atuação dos Profissionais em EAD: Estrutura e Metodologia. São Paulo: Pós- Graduação Lato Sensu UNIP, 2019. 105 p.

GONÇALVES, V. e-Learning: Reflexões sobre cenários de aplicação. In: IX Congresso da SPCE. Sociedade Portuguesa de Ciências da Educação, 2007.

GONZALEZ, M. Fundamentos da tutoria em educação a distância. São Paulo: Avercamp, 2009.

GOULART, E; VARGAS, H. Tecnologia, comunicação e produção cultural: o exemplo da música popular. In: CAPRINO, M. P (org.). Comunicação e Inovação: reflexões contemporâneas. São Paulo: Paulus, 2008.

GUIA do Estudante. Cinco características para ser bem-sucedido em um curso de EaD. Orientação Profissional, Universidades. 16 maio 2017. Disponível em: https://guiadoestudante.abril.com.br/universidades/cinco-caracteristicas- 
fundamentais-para-voce-ser-bem-sucedido-em-um-curso-de-ead/. Acesso em: 26 dez. 2019.

ICONIC-E-LEARNING-VECTOR. Vecteezy. 490 x 490 pixels, 72 dpi, 20,4 Kb, RGB, formato jpeg. Disponível em: https://www.vecteezy.com/vector-art/560110iconic-e-learning-vector. Acesso em 30 dez. 2019.

LUIZ, L. dos. S; SILVA, T. J. da. A Escola da Educação 3.0. SIMPEMAD-Simpósio Educação Matemática em Debate, v. 1, p. 149-149, 2014.

MARGALL, G. Educação 3.0 coloca o aluno no centro do processo de aprendizagem. CANALTECH. 13 de setembro de 2013. Disponível em: https://canaltech.com.br/mercado/Educacao-30-coloca-o-aluno-no-centro-doprocesso-de-aprendizagem/. Acesso em: 28 dez. 2019.

MEIR, J. As 6 características fundamentais da Geração Z. CONSUMIDOR MODERNO. 22 de Setembro de 2017. Disponível em: https://www.consumidormoderno.com.br/2017/09/22/caracteristicas-fundamentaisgeracao-z/. Acesso em: 20 dez. 2019.

MINISTÉRIO da Educação. PORTARIA N. 301, DE 7 DE ABRIL DE 1998. 9 de Abril de $1998 . \quad$ Disponível em: http://portal.mec.gov.br/seed/arquivos/pdf/tvescola/leis/port301.pdf. Acesso em: 29 dez. 2019.

MORAN, J. A Educação a Distância como Opção Estratégica. São Paulo: Summus Editorial, 2011. p. 52-58.

NAGY, A. C. B; GENGHINI, E. B. Didática do Ensino Superior e Produção de Conteúdo para Educação a Distância. São Paulo: Pós-Graduação Lato Sensu UNIP, 2019. 137 p. 
PIXABAY. Laptop, mulher, educação, estudo. 2019. Disponível em: https://pixabay.com/pt/photos/laptop-mulher-educa\%C3\%A7\%C3\%A3o-estudo3087585/. Acesso em: 24 dez. 2019.

PIXABAY. Notebook, local de trabalho, recepção. 2019. Disponível em: https://pixabay.com/pt/photos/notebook-local-de-trabalho-recep\%C3\%A7\%C3\%A3o336634/. Acesso em: 24 dez. 2019.

PIXABAY. Professor, propriedade. Disponível em: https://pixabay.com/pt/photos/professor-propriedade-3765909/. Acesso em: 24 dez. 2019.

PIAGET, J. O nascimento da inteligência na criança. 4. Ed. Rio de Janeiro: Zahar, 1982.

PRADO, M. E. B. B.; MARTINS, M. C. A mediação pedagógica em propostas de formação continuada de professores em informática na educação. In: VIII Congresso Internacional de Educação a Distância da ABED. Brasília, 2001.

SANTOS, B. C. Introdução à Educação a Distância. UNIP-interativa, 2016.

TORI, R. Educação sem distância: as tecnologias interativas na redução de distâncias em ensino e aprendizagem. São Paulo: Senac, 2010.

Enviado: Janeiro, 2020.

Aprovado: Janeiro, 2020. 